\title{
Long-wavelength GaInNAs/GaAs Vertical-cavity Surface-emitting Laser for Communication Applications
}

\author{
Faten A. Chaqmaqchee \\ Department of Physics, Faculty of Science and Health, Koya University, University Park, \\ Danielle Mitterrand Boulevard, Koya KOY45, Kurdistan Region - F.R. Iraq
}

\begin{abstract}
This paper presents a comprehensive study of optical and electrical properties of vertical-cavity surface-emitting lasers(VCSELS) for long wavelength communication applications. The device consists of GaInNAs/GaAs multi-quantum wells QWs that enclosed between standard top and bottom epitaxially grown on $\mathrm{AlGaAs} / \mathrm{GaAs}$ distributed Bragg reflectors. The impact of driven currents and injecting optical powers through QWs layers on the output light emission is addressed. Room temperature spectra measurements are performed at various applied currents using $980 \mathrm{~nm}$ pump laser and maximum intensity amplitude at around $21 \mathrm{~dB}$ was achieved.
\end{abstract}

Index Terms-Vertical-cavity surface-emitting lasers, GaInNAs/ GaAs, Light-current-voltage characterization, Optical pumping, Electrical pumping.

\section{INTRODUCTION}

Dilute nitride III-V alloys are becoming increasingly important for optoelectronic devices applications, such as lasers, modulators, photodetectors, and optical amplifiers for the $1.3 \mu \mathrm{m}$ window of optical fiber communication systems. One potentially important material for such applications is the quaternary alloy GaInNAs (Kondow, et al., 1996; Buyanova, et al., 2001; Chaqmaqchee, et al., 2011) or the quinary alloy GaInNAsSb (Korpijärvi, et al., 2015; Chaqmaqchee, et al., 2020). GaInNAs may be grown pseudomorphically on GaAs, allowing the use of highquality $\mathrm{Al}(\mathrm{Ga}) \mathrm{As} / \mathrm{GaAs}$ distributed Bragg reflectors (DBRs) (Chaqmaqchee and Balkan, 2014), with potential cost advantages over InP-based approaches due to their electronic structure can maintain stronger carrier confinement even at high temperatures (Hetterich, et al., 2000). Whereas there is no transport problem for the electrons in the $n$-type bottom $\mathrm{DBR}$, there is a serious problem for the holes in the $p$-type

ARO-The Scientific Journal of Koya University Volume VIII, No.1 (2020), Article ID: ARO.10627, 5 pages DOI: $10.14500 /$ aro. 10627

Received 29 January 2020; Accepted 27 June 2020

Regular research paper: Published: 30 June 2020

Corresponding author's e-mail: faten.chaqmaqchee@koyauniversity.org Copyright (C) 2020 Faten A. Chaqmaqchee. This is an open access article distributed under the Creative Commons Attribution License.
DBR due to larger effective mass, resulting in high series resistance in the VCSOA structures. Such a high resistance causes a major self-heating effect and reduces the flow through the DBR. Therefore, $p$-type compositional graded AlGaAs/GaAs DBR is designed for a peak reflectivity at 1.3 $\mathrm{mm}$ to overcome the poor hole conduction through the p-type DBR layer.

Dilute nitride structures have already found applications in several devices, such as high-performance laser diodes among which are cavity surface emitting lasers vertical-cavity surfaceemitting lasers (VCSELs) emitting in the $1.3 \mu \mathrm{m}$ window. VCSEL (Chaqmaqchee, 2019; Haghighi, et al., 2018) is driven above lasing threshold and shows some very interesting advantages over edge-emitting lasers and in plane SOAs (Pozo, et al., 2008). The vertical cavity geometry for such devices yields high coupling efficiency to optical fiber which is useful for achieving a low noise figure. It also allows for on chip testing techniques, single wavelength amplification, and two-dimensional array fabrication, hence lowering the power consumption and manufacturing cost. The narrower bandwidth of the vertical cavity structures makes the devices also good for filtering applications (Piprek, et al., 2001; Karim, et al., 2000).

The device is based on GaInNAs/GaAs material for operation in the $1.3 \mu \mathrm{m}$ wavelength range and has increased functionality using undoped DBRs. This coupled with direct injection into the active region is expected to yield improvements in the gain and bandwidth. The design of VCSEL devices is based on the transfer matrix method for multilayer structures (Yeh, 1991;
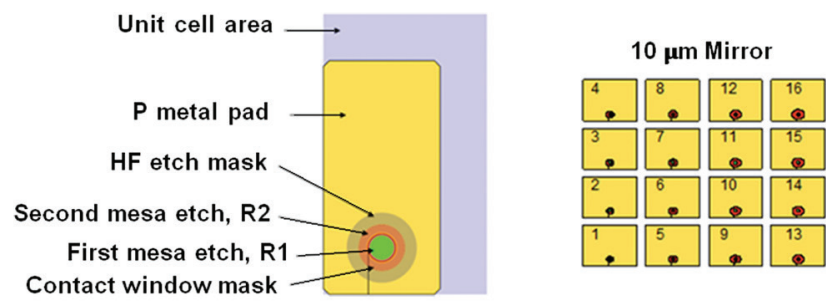

Fig. 1: Fabrication processes for vertical-cavity surface-emitting lasers (VCSELs) device including mask etch step, contact window mask and $\mathrm{Ti} / \mathrm{Pt} / \mathrm{Au}$ metallization with pad size of $120 \mu \mathrm{m} \times 200 \mu \mathrm{m}$, and pad-topad metal separation $50 \mu \mathrm{m}$ as in the right side. One set of 16 VCSEL devices with $10 \mu \mathrm{m}$ mirrors diameters as in the left side. 

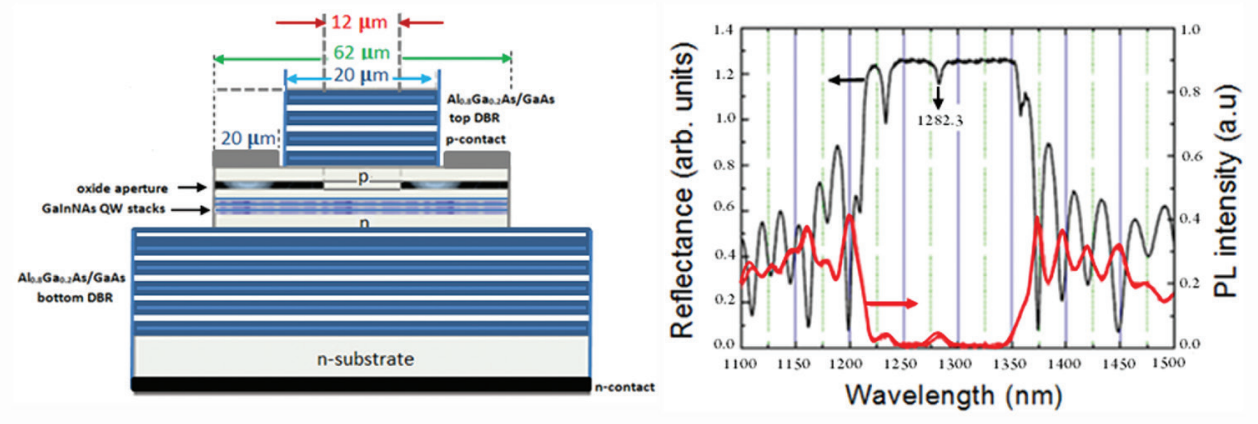

Fig. 2: The structure of the GaInNAs vertical-cavity surface-emitting laser coded G0428 with their PL intensity and reflectivity measurements at $300 \mathrm{~K}$.

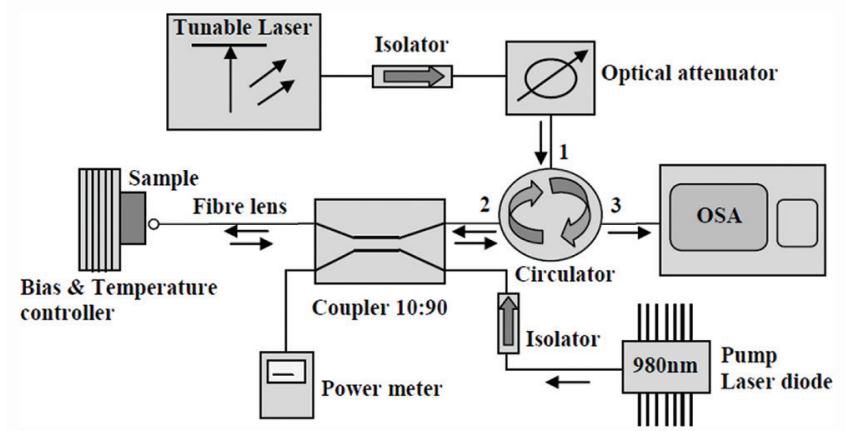

Fig. 3. Schematic of the vertical-cavity surface-emitting laser experimental setup used for optical pumping of top emitting device characterization under continuous-wave operation.

Shen, et al., 2019), and the optical field distribution within the structure, where the determination of the position of quantum wells is crucial. The operation of the devices is based on the injecting of the carriers (e-h) in their active region by the application of longitudinal electric fields. The emission light is always coming from the cathode region. However, the emitting region might be changed depending on the polarity of applied voltages (Wah and Balkan, 2004).

In this study, we have tested and demonstrated the operation of VCSEL devices based on dilute nitrides and to operate in the $1.3 \mu \mathrm{m}$ communication windows for metro and access networks applications. Output light-current-voltage (L-I-V) at different temperatures and spectra measurements at various applied currents was achieved. In addition, peak intensities of the VCSEL, input signal, and the combined VCSEL plus input signal at a fixed bias current of $12 \mathrm{~mA}$ and various input signal powers from 1 to $4 \mathrm{~mW}$ were studied.

\section{Materials AND Methods}

The fabrication procedure for VCSELs required a number of lithography steps, including etch steps to facilitate wafer bonding structure. In the first mesa mask, the planned radii are $10 \mu \mathrm{m}$ and $15 \mu \mathrm{m}$. In the second mesa mask, the planned radii are from $20 \mu \mathrm{m}$ to $36 \mu \mathrm{m}$ with step $1 \mu \mathrm{m}$. The total number of photolithography steps for all the devices could be reduced by combining the $\mathrm{S}_{\mathrm{i}} \mathrm{O}_{2}$ or $\mathrm{S}_{\mathrm{i}} \mathrm{N}_{\mathrm{x}}$ hard mask etch steps, including the contact window definition. Finally, a multilayer metallization system of titanium-platinum-gold ( $\mathrm{Ti} / \mathrm{Pt} / \mathrm{Au})$ was used. Titanium is used to promote adhesion between substrates

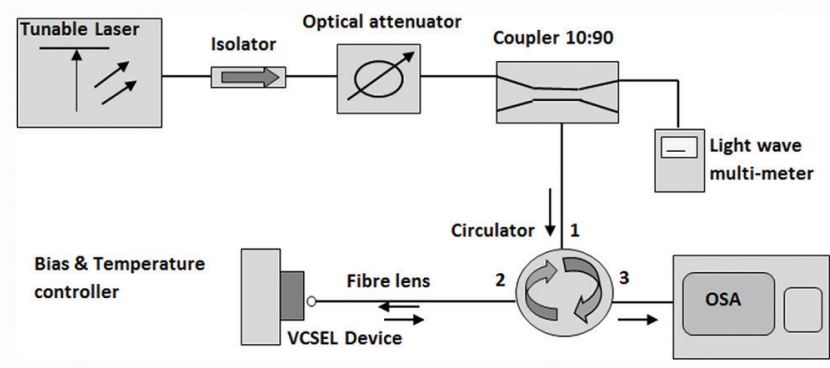

Fig. 4. The experiment setup of vertical-cavity surface-emitting laser for operation in the reflection mode through electrical pumping.

and sputtered gold films, which can diffuse up to the gold surface after annealing and then degrade the wire bondability (Harman, 1997). The proposed pad size is $120 \mu \mathrm{m} \times 200$ $\mu \mathrm{m}$, where pad to pad metal separation is around $50 \mu \mathrm{m}$. As depicted in Fig. 1, there are nine different sets of 16 devices, each set has a fixed mirror diameter (first mesa etch) of 10 $\mu \mathrm{m}$ and $15 \mu \mathrm{m}$, with etching of the confinement layer which was fabricated and each set has marked the above device. The radius of the second, electron confinement mesa (mesa 2) is different for each device within the set; therefore, the radius (R) and the diameter (D) of mesa 2 can be calculated by $\mathrm{R}=20 \mu \mathrm{m}+\{$ Device Number $\}$ and $\mathrm{D}=2 \times \mathrm{R}$ respectively.

Fig. 2 shows the GaInNAs/GaAs VCSEL structure including three elements. The bottom DBR mirror constitutes 24 pairs $\mathrm{Al}_{0.98} \mathrm{Ga}_{0.02} \mathrm{As} / \mathrm{GaAs}$ resulting in over $99.9 \%$ reflectivity. The top DBR mirror consists of 21 pairs of undoped $\mathrm{Al}_{0.8} \mathrm{Ga}_{0.2} \mathrm{As} / \mathrm{GaAs}$ quarter wavelength thick layers to provide $>99 \%$ reflectivity for the optical microcavity and gain region. The choice of 0.8 and $0.98 \mathrm{Al}$ content in the DBRs was to allow $0.98 \mathrm{Al}$ for the oxidation layer. The gain region is made of nine QWs that are distributed equally in three stacks of $7 \mathrm{~nm}$ thick $\mathrm{Ga}_{0.65} \mathrm{In}_{0.35} \mathrm{~N}_{0.02} \mathrm{As}_{0.98}$ QWs separated by $20 \mathrm{~nm}$ thick GaAs. The QWs were positioned at the antinodes of the field to provide resonant periodic gain and to maximize available gain. High gain and wider bandwidth can be achieved simultaneously by reducing the top mirror reflectivity of the device (Bjorlin, et al., 2001; Chaqmaqchee, et al., 2012). The photoluminescence PL intensity matches the cavity of reflectivity measurements at wavelength of $1282.3 \mathrm{~nm}$, as shown in the right side of Fig. 2.

In general, VCSELs can be optically pumped or electrically driven. Optical pumping is usually seen as a 

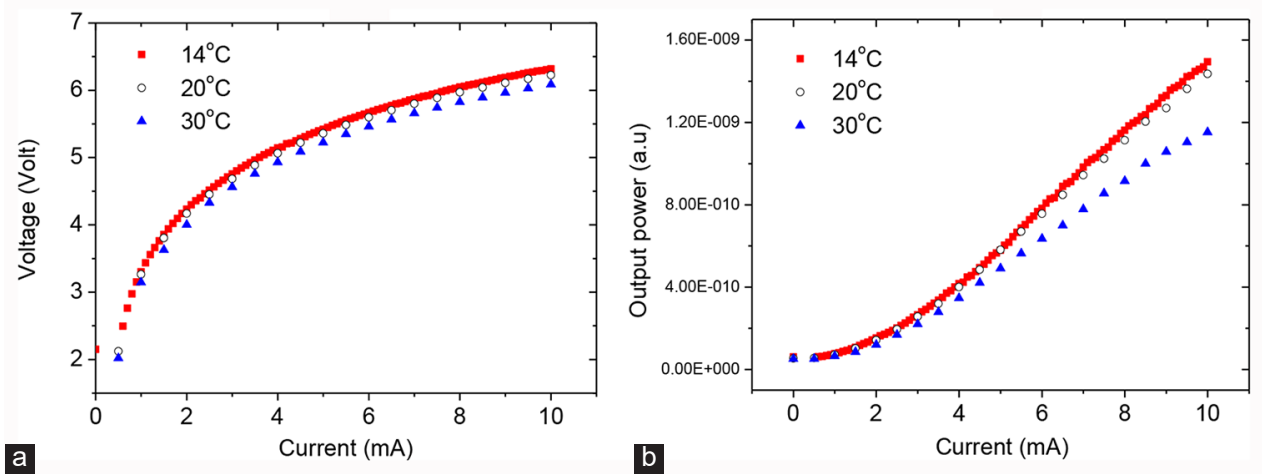

Fig. 5: Comparison of the three vertical-cavity surface-emitting laser temperatures for aperture diameter of $10 \mu \mathrm{m}$ (a) voltage-current (V I), and (b) light-voltage (LI) characteristics under CW operation.

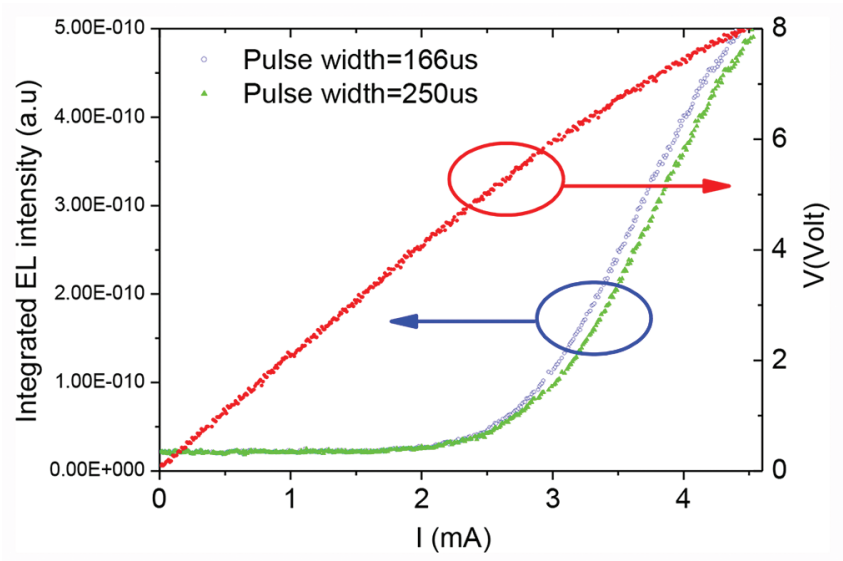

Fig. 6. Light-voltage-current characteristics of vertical-cavity surfaceemitting laser under pulsed operation with aperture diameter of $15 \mu \mathrm{m}$ and the second mesa etch diameter of $70 \mu \mathrm{m}$ at $\mathrm{T}=14^{\circ} \mathrm{C}$.

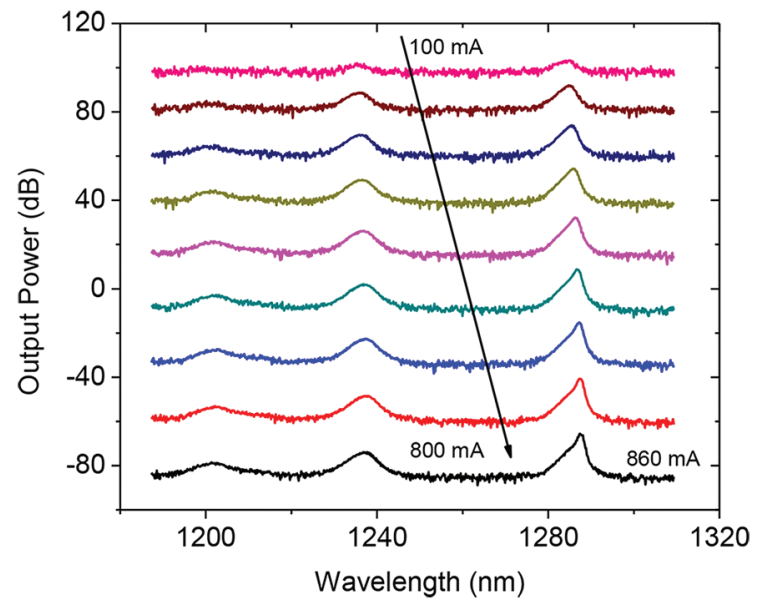

Fig. 7: The spectra of the vertical-cavity surface-emitting laser samples as a function of different applied currents between 100 and $860 \mathrm{~mA}$ at room temperature.

preliminary to electrical injection. The characterization of amplifiers was measured under continuous-wave (CW) pumping using the fiber-based system sketched in Fig. 3. The NI PXI-1033 tunable laser diode is used as an input signal source. The tunable laser wavelengths are varied from 1265 to $1345 \mathrm{~nm}$, whereas the output power is varied

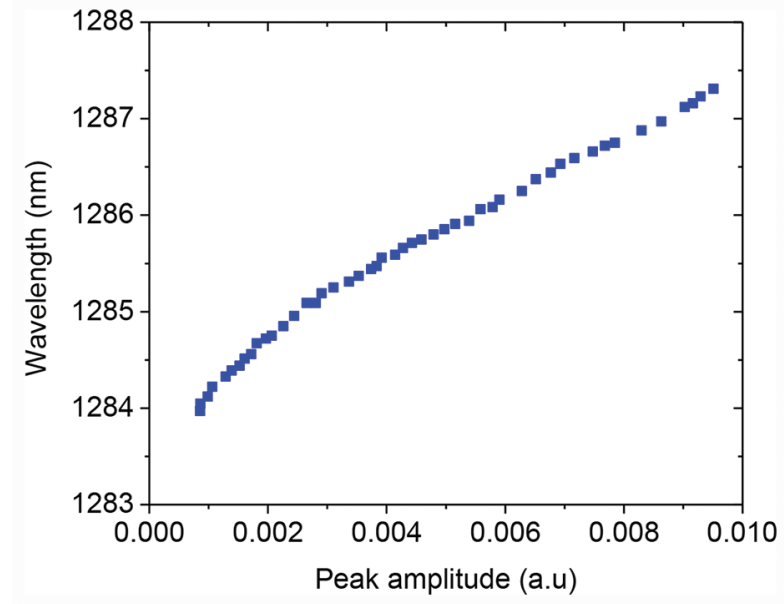

Fig. 8. Wavelength as a function of peak amplitude at room temperature.

from 1 to $6 \mathrm{~mW}$. The laser output power is controlled by the means of an optical variable attenuator. A single-mode fiber patch cord is used to connect one end of the isolator, and the other end is connected through an FC/APC adaptor to the port of an optical coupler, where the output power from the $90 \%$ coupler was about $85 \mathrm{~mW}$ to reach lasing threshold, whereas $10 \%$ split from the output power was measured on the power meter. A $980 \mathrm{~nm}$ fiber pigtailed single-mode diode laser (1999 PLM $980 \mathrm{~nm}$ pump module) is used for VCSEL excitation through a $980 \mathrm{~nm}$ isolator and an optical coupler. The output power from the laser is about $810 \mathrm{~mW}$ and is reduced to $<250 \mathrm{~mW}$ at the sample due to the losses through fibers. The laser signal passes through an isolator to prevent reflections and instabilities. The long focus fiber (with radius of $8 \mu \mathrm{m}$ ) is brought very close to the surface of the sample. The device under test is perfectly mounted on the temperature controlled heat sink fixed in a simple two-axis gimbal mount. The circulator is used as a special fiber-optic component to separate the amplified signal from the input signal and pump light. The circulator usually has three ports. The first port is connected to the optical attenuator and the second one is connected to the coupler and the last one is connected to the optical spectrum analyzer, which measures the optical power as a function of wavelength or frequency. In this case, the light 
intensity is exhibited as a function of wavelength over a fixed wavelength range (Chaqmaqchee, 2014).

Investigation of amplification performance was realized using an optical fiber system, as depicted in Fig. 4. A singlemode long-focus fiber with a diameter of $16 \pm 1 \mu \mathrm{m}$ was coupled to port 2 of the circulator using an FC/APC adapter, and the other end was positioned close to the GaInNAs VCSEL structure. A $1300 \mathrm{~nm}$ tunable laser is used as signal source with power not $>1 \mathrm{~mW}$ to inject the signals from the top mirrors using the long focus fiber. An ILX Lightwave laser diode controller was used as the current and temperature controller. The device is also pumped by an electrical bias under either $\mathrm{CW}$ or pulsed mode operation. The sample is mounted on the heat sink that is connected directly to the temperature controller for controlling the device temperature.

\section{Results AND Discussion}

Fig. 5 illustrates the temperature dependence of output L-I-V characteristics of the device with the VCSEL emitting at a wavelength of $1.3 \mu \mathrm{m}$ for an aperture diameter of 10 $\mu \mathrm{m}$ and the second mesa etch diameter is $60 \mu \mathrm{m}$. The device shows $\mathrm{CW}$ operation up to $30^{\circ} \mathrm{C}$ heat sink temperature. The emission occurred at bias current as low as $2 \mathrm{~mA}$ and no threshold current was observed and thus the device emitted spontaneously. Series resistance was high ranging from $50 \Omega$ to $150 \Omega$ and this might be due to the thin p-doped layer. As a result, no $\mathrm{CW}$ lasing was observed at room temperature.

Furthermore, the L-I-V characteristics of the VCSEL at temperature of $18^{\circ} \mathrm{C}$ have been measured under pulsed conditions using a pulse generator, as shown in Fig. 6. The pulse widths of $\mathrm{W}_{\text {puls }}=166$ and $250 \mu$ s are applied along the device of $70 \mu \mathrm{m}$ diameter, but no emissions were detected using the light wave multimeter.

Fig. 7 illustrates the spectra of VCSEL sample at various applied currents with the $980 \mathrm{~nm}$ pump laser and at a temperature of $15^{\circ} \mathrm{C}$. Fundamental mode shifts with increasing current form 100 to $800 \mathrm{~mA}$, and the maximum intensity amplitude at around $21 \mathrm{~dB}$ at peak wavelength of $1287.5 \mathrm{~nm}$ is recorded. Fig. 8 shows wavelength as a function of amplitude intensity and confirms the plot of Fig. 7, where the maximum intensity at peak wavelength of $1287.3 \mathrm{~nm}$ is observed.

Fig. 9 shows the peak intensities of the VCSEL, input signal, and the combined VCSEL plus input signal at a fixed bias current of $12 \mathrm{~mA}$ and various input signal powers from 1 to $4 \mathrm{~mW}$. The tuned wavelength laser was varied from $1292 \mathrm{~nm}$ to $1312 \mathrm{~nm}$. The peak intensities of the VCSEL have high amplitude at a wavelength of $1304 \mathrm{~nm}$ due to the cavity resonance. The peak intensities of the input signal were also recorded. Finally, the combined VCSEL plus input signal at various bias currents and input signal powers have been measured. Because the most change in device response occurs at the resonance wavelength, the gain evolution at the resonance wavelength as the input power is increased has been measured. However, no amplification was observed with injected power of $1,2,3$, and $4 \mathrm{~mW}$, first due to this, VCSEL was very promising and designed for electrically driven vertical cavity semiconductor optical amplifier and might be required a nano or few milliwatts of injected optical power to obtain high gain (Lisesivdin, et al., 2014). In addition, a significant problem can be encountered with electrically pumped GaInNAs VCSEL is the free carrier absorption in p-type DBRs that vary with wavelength (Harris, 2002).
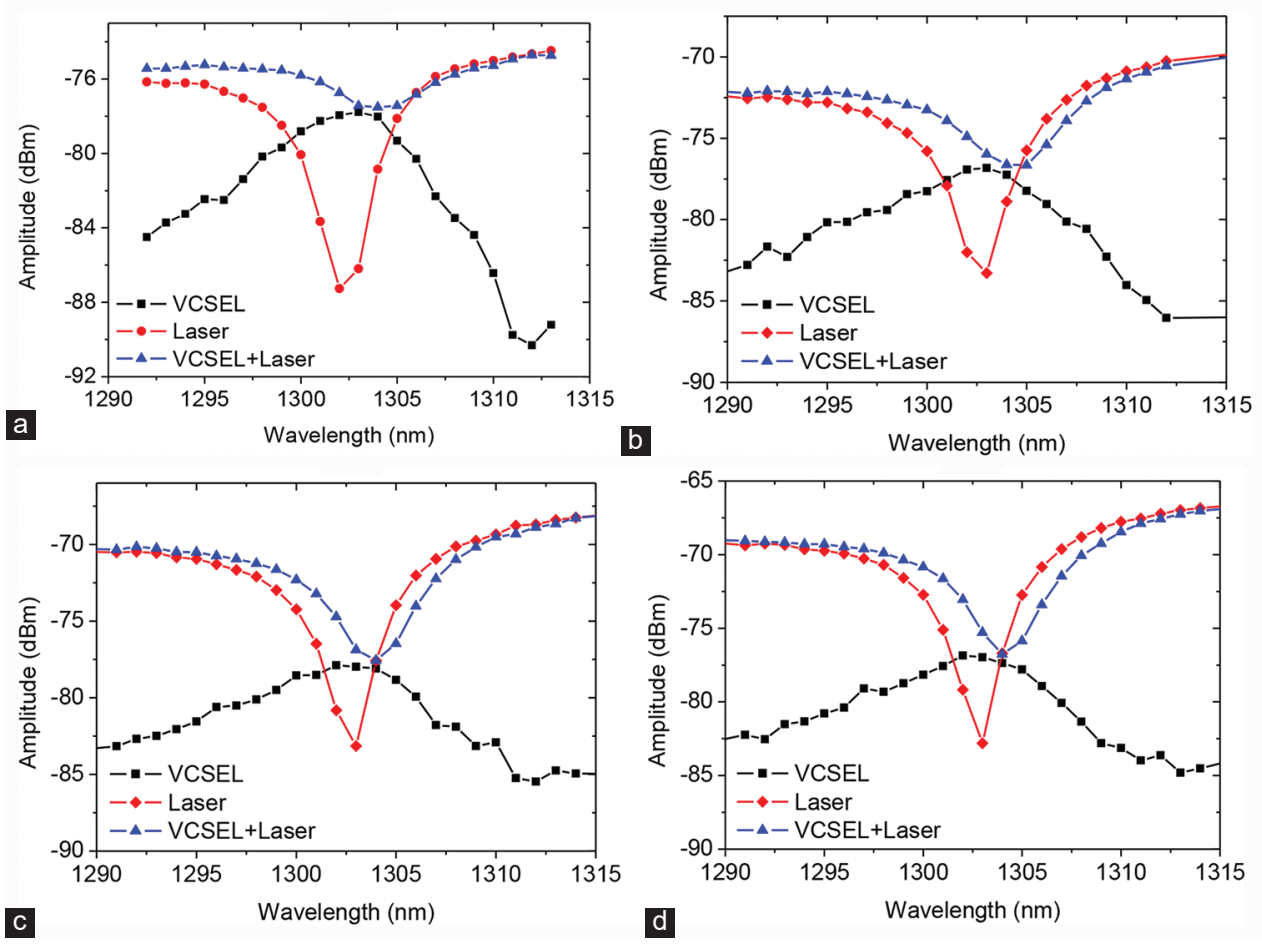

Fig. 9. Peak intensities of input signal, vertical-cavity surface-emitting laser (VCSEL), and the combined VCSEL and input signal were measured under fixed bias current of $12 \mathrm{~mA}$ and input powers: (a) $1 \mathrm{~mW}$, (b) $2 \mathrm{~mW}$, (c) $3 \mathrm{~mW}$, and (d) $4 \mathrm{~mW}$ and at $\mathrm{T}=14^{\circ} \mathrm{C}$. 


\section{CONCLUSION}

In this paper, we have tested GaInNAs/GaAs VCSEL devices in the $1.3 \mu \mathrm{m}$ communication windows. Optical and electrical characterizations at various applied currents and temperatures were achieved, respectively. In addition, the combine of VCSEL and input signal at fixed bias current and different input powers was studied. The highest peak intensity at around $21 \mathrm{~dB}$ for VCSEL in reflection mode is obtained using $980 \mathrm{~nm}$ pump laser. Thus, in an optically pumped VCSEL, further progress should be performed using high power to enhance the recombination process in the quantum wells, while using low injecting optical power to obtain high gain in an electrically driven dilute nitride VCSELs. Future improvements in performance can be achieved by further adapting the well-established $1300 \mathrm{~nm}$ VCSEL technology.

\section{ACKNOWLEDGMENT}

This work was funded by the Ministry of Higher Education and Scientific Research in Baghdad-Iraq. FC highly appreciates the support of University of Essex in Colchester-UK through this research. FC also acknowledges Koya University, Faculty of Science and Health, Department of Physics for allowing this study.

\section{REFERENCES}

Bjorlin, E.S., Riou, B., Abraham, P., Piprek, J., Chiu, Y.J., Black, K.A., Keating, A. and Bowers, J.E., 2001. Long wavelength vertical cavity semiconductor optical amplifiers. IEEE Journal of Quantum Electronics, 37(2), pp.274-281.

Buyanova, I.A., Chen, W.M. and Monemar, B., 2001. Electronic properties of Ga(In)NAs alloys. MRS Internet Journal Research Nitride Semiconductor, 6(2), pp.1-19.

Chaqmaqchee, F.A., 2014. Optically and electrically pumped of $\mathrm{Ga} 0.65 \mathrm{In} 0.35 \mathrm{~N} 0.02 \mathrm{As} 0.98 / \mathrm{GaAs}$ vertical-cavity surface-emitting lasers (VCSELs). The Arabian Journal for Science and Engineering, 39(7), pp.5785-5790.

Chaqmaqchee, F.A.I. and Balkan, N., 2012. Gain studies of 1.3- $\mu$ m dilute nitride HELLISH-VCSOA for optical communications. Nanoscale Research Letters, 7(526), pp.1-4.

Chaqmaqchee, F.A.I. and Balkan, N., 2014. Ga0.35In0.65 N0.02As0.08/GaAs bidirectional light-emitting and light-absorbing heterojunction operating at 1.3 $\mu \mathrm{m}$. Nanoscale Research Letters, 9(37), pp.1-5.

Chaqmaqchee, F.A.I., 2019. Performance characteristics of conventional vertical cavity surface emitting lasers VCSELs at $1300 \mathrm{~nm}$. ZANCO Journal of Pure and Applied Sciences, 31(2), pp.14-18.

Chaqmaqchee, F.A.I., Mazzucato, S., Oduncuoglu, M., Balkan, N., Sun, Y., Gunes, M., Hugues, M. and Hopkinson, M., 2011. GaInNAs-based Hellishvertical cavity semiconductor optical amplifier for $1.3 \mu \mathrm{m}$ operation. Journal
Nanoscale Research Letters, 6(104), pp.1-7.

Chaqmaqchee, F.A.I., Mazzucatoa, S., Sun, Y., Balkan, N., Tiras, E., Hugues, M. and Hopkinson, M., 2012. Electrical characterisation of p-doped distributed Bragg reflectors in electrically pumped GaInNAs VCSOAs for $1.3 \mu \mathrm{m}$ operation. Journal Materials Science and Engineering B, 177(10), pp.739-743.

Chaqmaqchee, F.A.I., Salh, S.A.A. and Sabri, M.F.M., 2020. Optical analysis of $1300 \mathrm{~nm}$ GaInNAsSb/GaAs vertical cavity semiconductor optical amplifier. ZANKO Journal of Pure and Applied Sciences, 32(2), pp.87-92.

Haghighi, N., Rosales, R., Larisch, G., Marcin, G., Frasunkiewicz, L., Czyszanowski, T. and Lott, J.A., 2018. Simplicity VCSELs. Proceedings of SPIE, 10552, pp.1-9.

Harman, G.G., 1997. Wire Bonding in Microelectronics: Material, Processes, Reliability and Yield. McGraw-Hill, New York.Available from: https://www. bookdepository.com/Wire-Bonding-Microelectronics-Materials-ProcessesReliability-Yield-George-Harman/9780070326194. [Last accessed on 2019 Dec 10].

Harris, J.S.Jr., 2002. GaInNAs long-wavelength lasers: Progress and challenges. Semiconductor Science and Technology, 17(8), pp.880.

Hetterich, M., Dawson, M.D., Egorov, A., Bernklau, D. and Riechert, H., 2000. Electronic states and band alignment in GalnNAs/GaAs quantum-well structures with low nitrogen content. Applied Physics Letters, 76(8), pp.1030.

Karim, A., Bjorlin, S., Piprek, J. and Bowers, J.E., 2000. Long-wavelength vertical-cavity lasers and amplifiers. IEEE Journal of Selected Topics in Quantum Electronics, 6(6), pp.1244-1253.

Kondow, M., Uomi, K., Niwa, A., Kitatani, T., Watahiki, S. and Yazawa, Y., 1996. GaInNAs: A novel material for long-wavelength-range laser diodes with excellent high-temperature performance. Japanese Journal of Applied Physics, 35(2B), pp.1273.

Korpijärvi, V., Kantola, E.L., Leinonen, T., Isoaho R. and Guina, M., 2015. Monolithic GaInNAsSb/GaAs VECSEL operating at $1550 \mathrm{~nm}$. IEEE Journal of Selected Topics in Quantum Electronics, 21(6), pp.480-484.

Lisesivdin, S.B., Khan, N.A., Mazzucato, S., Balkan, N., Adams, M.J., Korpijärvi, V.M., Guina, M., Mezosi, G. and Sorel, M., 2014. Optical gain in $1.3-\mu \mathrm{m}$ electrically driven dilute nitride VCSOAs. Nanoscale Research Letters, 9(22), pp.1-5.

Piprek, J., Bjorlin, E.S. and Bowers, J.E., 2001. Optical gain-bandwidth product of vertical cavity laser amplifiers. Electronics Letters, 37(5), pp.298-299.

Pozo, J., Vogiatzis, N., Ansell, O., Hearda, P.J., Rorison, J.M., Tuomistoc, P., Konttinen, J., Saarinen, M., Peng, C., Viheriälä, J., Leinonen, T. and Pessa, M., 2008. Fabrication and characterization of GaInNAs/GaAs semiconductor optical amplifiers. Proceedings of SPIE, 6997, pp.1-9.

Shen, C.C., Hsu, T.C., Yeh, Y.W., Kang, C.Y., Lu, Y.T., Lin, H.W., Tseng, H.Y., Chen, Y.T., Chen, C.Y., Lin, C.C., Wu, C.H., Lee, P.T., Sheng, Y., Chiu, C.H. and Kuo, H.C., 2019. Design, modeling, and fabrication of high-speed VCSEL with data rate up to $50 \mathrm{~Gb} / \mathrm{s}$. Nanoscale Research Letters, 14(276), pp.1-6.

Wah, J.Y. and Balkan, N., 2004. Low field operation of hot electron light emitting devices: Quasi-flat-band model. IEE Proceedings Optoelectronics, 151(6), pp.482-285.

Yeh, P., 1991. Optical Waves and Layered Media. John Wiley and Sons, New York. Available from: https://www.wiley.com/en-us/optical+waves +in+ layered+media-p-9780471731924. [Last accessed on 2019 Dec 10]. 